CONF-910162--2

DE91 007835

\title{
GELCAST ZIRCONIA-ALUMINA COMPOSITES
}

\section{O. O. Omatete, A. Bleier, C. G. Westmoreland, and A. C. Young Oak Ridge National Laboratory Oak Ridge, TN 37831}

\section{DISCLAIMER}

\begin{abstract}
This report was prepared as an account of work sponsored by an agency of the United States Government. Neither the United States Government nor any agency thereof, nor any of their employees, makes any warranty, express or implied, or assumes any legal liability or responsibility for the accuracy, completeness, or usefulness of any information, apparatus, product, or process disclosed, or represents that its use would not infringe privately owned rights. Reference herein to any specific commercial product, process, or service by trade name, trademark, manufacturer, or otherwise does not necessarily constitute or imply its endorsement, recommendation, or favoring by the United States Government or any agency thereof. The views and opinions of authors expressed herein do not necessarily state or reflect those of the United States Government or any agetcy thereof.
\end{abstract}

\section{5th Annual Conference on Composites and Advanced Ceramics Cocoa Beach, Florida \\ January 1991}

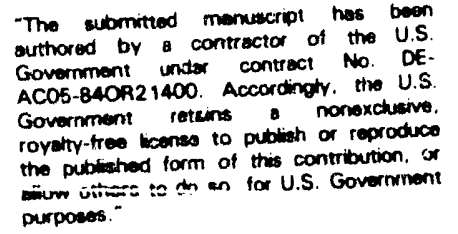


GELCAST ZIRCONIA-ALUMINA COMPOSITES*

O. O. Omatete, A. Bleier, C. G. Westmoreland, and A. C. Young

Oak Ridge National Laboratory

Oak Ridge, TN 37831

\section{ABSTRACT}

Near net-shaped parts of zirconia-alumina composites have been successfully formed by gelcasting, a technique which utilizes in situ polymerization of acrylamide monomers. The high solids loading required for gelcasting ( $\sim 50$ vol \%) was obtained by controlling the $\mathrm{pH}$-dependent stability of the aquecus zirconia-alumina suspensions. A strong correspondence was found among the surface charges on the particles, colloidal stability, and the maximum solids loading.

\section{INTRODUCTION}

The traditional fabrication of ceramic parts is limited to several forming procedures such as pressing, slip casting, and injection molding. Although each technique possesses merits, none on its cwn is capable of meeting today's challenges such as reproduciblity, reliability, and fabricability. Recently, a new forming process named "gelcasting" was developed.1-3 Gelcasting is a near-net-shape, forming technique and is based on ideas borrowed from traditional ceramic processing and from polymer chemistry. It is a generic process which can be carried out readily in available equipment. Thus, it requires a minimum departure from conventional, ceramic manufacturing practice.

Unlike sol-gel forming in which the ceramic material is synthesized during the processing, gelcasting uses commercially available ceramic powder suspended in a solution of organic monomers. After casting, the solution is polymerized to form a strong, crosslinked, polymer-water gel

"Research sponsored by the Division of Materials Sciences, U.S. Department of Energy, under contract DE-AC05-84OR21400 with Martin Marietta Energy Systems, Inc. 
filled with the powder. The polymerization permanently immobilizes the powder in the desired shape. Drying yields parts containing only about $3 \mathrm{wt} \%$ polymer compared to about $30 \mathrm{wt} \%$ binder in injection molding.

Rapid or excessive shrinkage during the drying of gelcast parts produces warped or cracked bodies. The higher the solids loading, the less the green body shrinks during drying. Consequently, a requirement of the process is a castable suspension with a solids loading of at least $50 \mathrm{vol} \%$ in order to minimize damage during drying. Dispersion of the powders in the gelcasting solution is an important process that must be controlled in order to produce a castable suspension with desirably high solids loading.

In this investigation, binary zirconia-alumina composite parts were produced by gelcasting because of their relevance to zirconia-toughened alumina applications. However, the effect of gelcasting suspension conditions and relative concentrations of the solid components on the stabilization of zirconia and alumina particulates has not been studied in detail. Specific processing problems previously identified relate to the tendency of the particulates, especially that of zirconia, 4 to cluster and form agglomerates held together by strong van der Waals forces. These clusters limit the maximum concentration of solid that can be incorporated into a ceramic slurry and generate large voids when the powder is consolidated. The maximum concentration of solid that can be achieved in a slurry is characterized by the particle concentration limit that makes the slurry nonpourable and pastelike. In unary $\mathrm{ZrO}_{2}$ suspensions, this limit had previously been found to occur in the range of 20 to $30 \mathrm{vol} \% \mathrm{ZrO}_{2}$ in gelcasting solution.5

The negative effect of aggiomerates is more acute in binary suspensions of zirconia and alumina. For a mixture of equal-sized particles that have the same surface potential, the van der Waals forces between neighboring zirconia particles are stronger than those for alumina and lead to relatively more coagulation for this material. 6 Additionally, clustering of alumina particles can be promoted by zirconia, even under conditions for which the alumina is colloidally stable. This behavior, in which the less stable component controls the overall stability of the binary mixture, has been theoretically explained7-9 and experimentally verified for a wide variety of systems.10-13

Until now, only monolithic ceramics have been gelcast.3,14 A major objective of the present effort, therefore, was to demonstrate that 
composites can be gelcast into complex shapes, confirming that the process is generic. Concomitant objectives are to increase the maximum solids loading of zirconia significantly in unary slurries, and to investigate the effect of $\mathrm{pH}$ and relative oxide composition on the maximum loading in the zirconia-alumina binary system.

The suspension $\mathrm{pH}$ is a critical parameter in these systems. Particles of zirconia interact with an aqueous solution and establish a surface charge that, if of sufficier. ${ }^{4} y$ large magnitude, effectively counteract the van der Waals forces that promote clustering, thereby, providing electrostatic stabilization. The degree of surface interaction, and the resultant surface charge, depend on $\mathrm{pH}$.

\section{EXPERIMENTAL MATERIALS AND PROCEDURES}

Materials: - Table 1 summarizes selected physical and chemical properties of the zirconia and alumina powders used. The mean diameters were obtained from sedimentation data.* Specific surface area was measured by gas adsorption** and the isoelectric points were determined electrophoretically as described later.

The chemicals used in the gelcasting process are the same as those recently described for alumira ceramics by Omatete and co-workers.2,3 These reagents are the acrylamide monomer $\left[\mathrm{CH}_{2}=\mathrm{CHCONH}_{2}\right]$, tha crosslinking agent, $\mathrm{N}, \mathrm{N}^{\prime}$-methylene bisacrylamide $\left[\left(\mathrm{CH}_{2}=\mathrm{CHCONH}\right)_{2} \mathrm{CH}_{2}\right]$, and the free-radical initiator, ammonium persulfate [( $\left.\left(\mathrm{NH}_{4}\right)_{2} \mathrm{~S}_{2} \mathrm{O}_{8}\right]$. A solution of the monomer and the crosslinking agent in water constitutes the premix. Hydrochloric or nitric acid and tetramethylammonium hydroxide (TMAOH), [( $\left.\left(\mathrm{CH}_{3}\right)_{4} \mathrm{~N}+\mathrm{OH} \cdot\right]$, were used to adjust $\mathrm{pH}$. Distilled, deionized water was used in all experiments.

Procedures: The relative suspension heights (RSH) of various slurries were evaluated at intervals up to two weeks and represent the effect of gravity on the particulates in the suspension. These measurements were taken on quiescent suspensions in which the concentrations of $\mathrm{ZrO}_{2}$ and $\mathrm{Al}_{2} \mathrm{O}_{3}$ were initially 3.5 and 5.0 vol \%,

${ }^{*}$ Centrifugal particle size analyzer, Model 500, Horiba Instruments, Inc., Irvine, CA.

"Quantasorb Sorption System, Quantachrome Inc., 6 Aerial Way, Syosset, NY. 
respectively. The height of the demarcation between the turbid, lower region and the clear, upper region in cylindrical containers was measured and normalized to the overall height of the sample.

At short times, RSH values near unity indicate that virtually no settling has occurred and that the suspension is colloidally stable, whereas, low RSH values denote colloidally unstable systems because particulate clusters settle faster than their constituent primary particles. Note that the term, $1 / \mathrm{RSH}$, represents the degree to which a suspension is concentrated during gravitational sedimentation.

At long times, the relationship between stability and RSH is reversed. Colloidally stable slurries form sediments possessing a high volume fraction of solid, owing to efficient packing of particulates that often approach the maximum, attainable consolidation. These systems now exhibit low RSH value's. Unstable slurries, on the other hand, contain clusters than do not pack efficiently and, therefore, have higher RSH values at extended age.

Electrophoretic mobility, $\mu_{E}$, was measured in $0.01 \mathrm{~mol} / \mathrm{dm}^{3} \mathrm{NaCl}$ at $25^{\circ} \mathrm{C}$ using an automated analyzer* to determine the $\mathrm{pH}$ sensitivity of the surface charge responsible for the stability phenomena. Small samples of the concentrated suspensions were diluted at the desired $\mathrm{pH}$ values and ultrasonicated prior to measurement.

The maximum loading is the concentration of a solid that can be dispersed in a suspension, while maintaining sufficient fluidity to ensure that the slurry was pourable. A fluid and pourable slurry which can fill all the parts of a mold is necessary to form good gelcast parts. The maximum loading was determined qualitatively for each oxide by incorporating increasing amounts of powder into a suspension until it had prohibitively high viscosity and became pastelike. This loading was evaluated under selected $\mathrm{pH}$ conditions. The maximum loading was also determined for binary mixtures of $20 \mathrm{vol} \% \mathrm{ZrO}_{2}$ and $80 \mathrm{vol} \% \mathrm{Al}_{2} \mathrm{O}_{3}$. As mentioned earlier, to minimize shrinkage, a value of $50 \mathrm{vol} \%$ is chosen as the minimum concentration of solid that is typically acceptable for gelcasting.

The forming process consisted of preparing selected, concentrated unary and binary suspensions in the gelcast premix and then adding the initiator. These suspensions were cast in either plastic or metal molds.

"System 3000, Pen Kem, Bedford Hills, NY. 
For the binary systems, several gelation conditions were examined: 11.9 to $13.8 \mathrm{wt} \%$ monomer, 0.51 to $0.59 \mathrm{wt} \%$ crosslinker, 0.025 to $0.04 \mathrm{wt} \%$ initiator, $\mathrm{pH} 3.9$ to 4.7 , and ambient temperature or $1 \mathrm{~h}$ at 55 to $65^{\circ} \mathrm{C}$, to determine if they would gel and produce acceptable green bodies. The green bodies were then dried at room temperature in a constant humidity chamber. Based on this examination, the most important parameters are the initiator concentration and the gelation temperature. Therefore, a cylindrical piston $(6.35 \mathrm{~cm}$ in diam and $6.35 \mathrm{~cm}$ in height) with a hole $\left(0.95 \mathrm{~cm}\right.$ in diam) was cast using a slurry of 20:80 mixture $\mathrm{ZrO}_{2}$ to $\mathrm{Al}_{2} \mathrm{O}_{3}$ at $55 \mathrm{vol} \%$ loading prepared at $\mathrm{pH} 4.5$. The piston was gelled in an oven at $65^{\circ} \mathrm{C}$ for one hour.

\section{RESULTS}

Suspension Properties: Figure $1(a)$ summarizes the sedimentation data. The behaviors of $\mathrm{ZrO}_{2}$ and $\mathrm{Al}_{2} \mathrm{O}_{3}$, expressed as a function of $\mathrm{pH}$, are qualitatively similar. For $\mathrm{ZrO}_{2}$, the data indicate that, for aging times of $1 \mathrm{~h}, \mathrm{pH}$ conditions less than 6.5 (Region I) and those greater than 11.5 (Region III) promote stability, i.e., high RSH values that reflect limited settling of $\mathrm{ZrO}_{2}$. The conditions between these two $\mathrm{pH}$ values (Region II), denoted by hatching, induce clustering of the $\mathrm{ZrO}_{2}$ particles and the rapid settling that produces low RSH values.

Similarly, the $\mathrm{RSH}$ plot for $\mathrm{Al}_{2} \mathrm{O}_{3}$ in Figure $1(a)$ shows three distinct regions of varying stability. In this case, the $\mathrm{pH}$ values that represent the transition between Region II, and Regions I and III, respectively, are 7.1 and $>12.5$.

Sedimentation data for each solid collected for an aging time of 2 weeks (not shown here because $1-h$ data relates more appropriately to the gelcasting procedures) demonstrates that the systems which stay suspended the longest also pack most efficiently, yielding low RSH values after long aging times. This behavior underscores the high degree of colloidal stability for each solid within Regions I and III.

Figure $1(b)$ summarizes the $\mathrm{pH}$-dependent electrophoretic mobility data for the powders. Though differences exist between these profiles, each powder exhibits similar general amphoteric behavior. Each has an isoelectric point $\left(\mathrm{pH}_{i e p}\right)$ at which the surface charge is zero. This occurs at $\mathrm{pH} 7.5$ for $\mathrm{ZrO}_{2}$ and 8.7 for $\mathrm{Al}_{2} \mathrm{O}_{3}$. Also, the surface charge of each powder is positive when the $\mathrm{pH}$ is less than $\mathrm{pH}_{i e p}$ and negative when it is 
greater. Finally, the surface charge of each oxide is maximized at $\mathrm{pH} \ll$ $\mathrm{pH}_{\text {iep }}$ and $\mathrm{pH} \gg \mathrm{pH}_{\text {iep }}$, but the saturation limit for positively charged particles exceeds that for the negatively charged ones.

Maximum Loading: The open symbols in Fig. 2 summarize the maximum loading data for $\mathrm{ZrO}_{2}$ and $\mathrm{Al}_{2} \mathrm{O}_{3}$. The dashed line represents $50 \mathrm{vol} \%$, a minimum acceptable loading for gelcasting. As the plots show, each solid exhibits a strong pH-dependent profile. The data demonstrate that each unary system possesses two regimes, one at low pH (Region I) and the other at high pH (Region III) within which its maximum loading is respectively optimized for positively and negatively charged particles (Fig. 2). Between these two extreme conditions, each possesses one regime in which maximum loading is minimum for each sign of surface charge (Region II). The $\mathrm{pH}$ at the lowest value of the maximum loading is 7.0 for $\mathrm{ZrO}_{2}$ and 8.2 for $\mathrm{Al}_{2} \mathrm{O}_{3}$. These $\mathrm{pH}$ values relate well to the isoelectric points.

Comparison of the data from Figs. 1 and 2 shows a strong correspondence among the surface charges on the particles, colloidal stability, and the maximum loading. Regions of stability, I and III, in Fig. 1, provide conditions that maximize solids loading; compare these with Regions $\mathrm{I}$ and III in Fig. 2. Stability and loading are maximized by achieving the highest mobility.

The filled symbols in Fig. 2 summarize the maximum solids loading data for binary systems comprised of $20 \mathrm{vol} \% \mathrm{ZrO}_{2}$ and 80 vol $\% \mathrm{Al}_{2} \mathrm{O}_{3}$. Like the unary suspensions, the binary one exhibits a strong $\mathrm{pH}$-dependent profile. Its profile resembles those of the constituent oxides and generally resides within the range between those of $\mathrm{ZrO}_{2}$ and $\mathrm{Al}_{2} \mathrm{O}_{3}$. Table 2 shows this relationship quantitatively in terms of the $\mathrm{pH}$ values that correspond to the transitions between Region II and Regions I and III. The $\mathrm{pH}$ that provides the lowest value of maximum loading for each system is also included in this table. Comparison of these values with the $\mathrm{pH}_{\text {iep }}$ in Table 1 indicates that the lowest values of maximum loading of unary suspensions are determined by $\mathrm{pH}_{\text {iep }}$.

Gelation: Figure 3 shows the dried piston gelcast from the $\mathrm{ZrO}_{2}$ $\mathrm{Al}_{2} \mathrm{O}_{3}$ composite. There has been about $3 \%$ net linear shrinkage relative to the dimension of the mold, a value comparable to that reported for the dried parts of a $55 \mathrm{vol} \%$ alumina system. 3 The curvature and the interpenetrating hole have been retained without significant distortion demonstrating isotropic shrinkage. 


\section{DISCUSSION}

The data indicate that $\mathrm{pH}$ must be sufficiently acidic for the concentrations in suspensions of $\mathrm{ZrO}_{2}, \mathrm{Al}_{2} \mathrm{O}_{3}$, and the 20:80 binary mixture to meet or exceed the required 50 vol \% value (Fig. 2). The specific useful $\mathrm{pH}$ range shown in Table 2, varies with the type of oxide in unary systems and with the ratio of their relative concentrations in the binary mixture but represents conditions under which each particle possesses a positive surface charge. Under these conditions, the surface charge of the powder gen rrates an electrostatic repulsion that prevents van der Waals forces from stabilizing clusters. The binary composition investigated seems adequately pourable for gelcasting purposes. This quality implies that the viscosity is sufficiently low for practical concerns.

The $\mathrm{pH}$ of the suspension is central to the establishment of the surface charge that (1) ensures stability of a slurry, (2) reduces sedimentation rate, and (3) maximizes the solids loading and the related volume fraction on packing. This study shows that the relative concentration of the two oxides in the binary composite determines, in part, the $\mathrm{pH}$ range over which a suspension is stable and that $\mathrm{ZrO}_{2}$ dominates this range by determining as Table 2 emphasizes, the transition between Regions I and II of Figure 2.

Figure 2 shows that the difference between the $\mathrm{pH}$ of gelcasting and the isoelectric points determines the maximum loading of solids. The higher the absolute value of this difference, the higher the maximum solids loading. The maximum loading for each powder asymptotically approaches its highest value in the $\mathrm{pH}$ range below its isoelectric point. For the $20: 80$ vol $\% \mathrm{ZrO}_{2}-\mathrm{Al}_{2} \mathrm{O}_{3}$ mixture, the best gelcasting conditions exist if the $\mathrm{pH} \ll \mathrm{pH}_{\text {iep }} \mathrm{ZrO}_{2}$.

To establish gelcasting guidelines for unary $\mathrm{ZrO}_{2}, \mathrm{Al}_{2} \mathrm{O}_{3}$, and their binary mixtures, measurement of certain properties of the powders are desirable. These include (1) the electrophoretic mobility or other properties that directly relate to the minimum surface charge needed for stabilization of the suspension, (2) the specific surface area of the powder, and (3) the particle-size distribution. The first type of data indicates the range of acceptable $\mathrm{pH}$ for high solids loading. The second and third ones relate to the capacity of the available solid surface to accommodate gelation reagents if the interaction between them and the 
surface favors adsorption to the maximum degree of packing attainable. This study has focussed on (1) and its $\mathrm{pH}$ dependence.

The study will be continued to produce sintered $\mathrm{ZrO}_{2}-\mathrm{Al}_{2} \mathrm{O}_{3}$ parts. The microstructure and other properties of the sintered parts will be determined.

\section{CONCLUSIONS}

The data presented herein lead to the following conclusions regarding the gelcasting of $\mathrm{ZrO}_{2}-\mathrm{Al}_{2} \mathrm{O}_{3}$ composites into complex-shaped parts and the preparation of concentrated, colloidally stable $\mathrm{ZrO}_{2}, \mathrm{Al}_{2} \mathrm{O}_{3}$, and binary $\mathrm{ZrO}_{2}-\mathrm{Al}_{2} \mathrm{O}_{3}$ suspensions.

1. Gelcasting is applicable to ceramic composites, in addition to monolithic ceramics. The $\mathrm{ZrO}_{2}-\mathrm{Al}_{2} \mathrm{O}_{3}$ piston demonstrates that complexshaped, composite parts can be gelcast.

2. The suspension $\mathrm{pH}$ is a critical processing parameter for determining the maximum concentration of solid that can be suspended; the difference between the $\mathrm{pH}$ of gelcasting and the isoelectric points $\left(\mathrm{pH}_{\text {iep }}\right)$ determines the maximum loading of solids. Best conditions for gelcasting $20: 80$ vol $\% \mathrm{ZrO}_{2}: \mathrm{Al}_{2} \mathrm{O}_{3}$ exist if $\mathrm{pH} \ll \mathrm{pH}_{\text {iep }}\left(\mathrm{ZrO}_{2}\right)$.

3. Generally, the maximum loading of solid increases by increasing the absolute value of the difference $\mathrm{pH}-\mathrm{pH}_{\text {iep }}$, asymptotically approaching the highest value for a given powder in the $\mathrm{pH}$ range below its isoelectric point.

\section{ACKNOWLEDGEMENTS}

The authors thank Drs. H.T. Lin, M. A. Janney, A. J. Moorhead, and P. F. Becher for reviewing the manuscript and are grateful for their comments. 


\section{LIST OF TABLES}

Table 1. Physical and chemical properties of zirconia and alumina powders

Table 2. Critical maximum loading $\mathrm{pH}$ values from Fig. 2.

\section{FIGURES}

Fig. 1. (a) Sedimentation behavior of unary $\mathrm{ZrO}_{2}$ and $\mathrm{Al}_{2} \mathrm{O}_{3}$ suspensions initially at 3.5 and 5.0 vol \% respectively. Relative Suspension Height (RSH) vs $\mathrm{pH}$ after $1 \mathrm{~h},(b)$ Electrophoretic mobility, $\mu_{E}$, of $\mathrm{ZrO}_{2}$ and $\mathrm{Al}_{2} \mathrm{O}_{3}$ suspensions in $0.01 \mathrm{~mol} / \mathrm{dm}^{3} \mathrm{NaCl}$ vs $\mathrm{pH}$.

Fig. 2. Maximum loading for $\mathrm{ZrO}_{2}$ (open circles), $\mathrm{Al}_{2} \mathrm{O}_{3}$ (open triangles), and a binary mixture, $1: 4$ (solid circles) $\mathrm{ZrO}_{2}: \mathrm{Al}_{2} \mathrm{O}_{3}$, vol \% of overall mixture vs $\mathrm{pH}$.

Fig. 3. Dried, composite piston, gelcast from 20:80 vol \% $\mathrm{ZrO}_{2}-\mathrm{Al}_{2} \mathrm{O}_{3}$ suspension. 
Table 1. Physical and chemical properties of zirconia and alumina powders

$\begin{array}{lll} & \text { Zirconia } & \text { Alumina } \\ \text { Supplier } & \text { Tosoha } & \text { Reynolds } b \\ \begin{array}{l}\text { Designation } \\ \text { Lot No. }\end{array} & \text { TZ-3YS } & \text { RCHP-DPM } \\ & \mathrm{S} 308043 \mathrm{P} & \mathrm{BM}-2216 \\ \text { Typical Composition } & \mathrm{t}-\mathrm{ZrO}_{2} & \alpha-\mathrm{Al}_{2} \mathrm{O}_{3} \\ \mathrm{Y}_{2} \mathrm{O}_{3}, \mathrm{wt} \%(\mathrm{~mol} \%) & 5.48(3.04) & - \\ \text { Surface Area, }(\mathrm{in} 2 / \mathrm{g})^{c} & 6.37 & 6.98 \\ \text { Mean Diameter, }(\mu \mathrm{m}) \mathrm{c} & 0.39 & 0.55 \\ \text { Isoelectric point }(\mathrm{pH}) c & 7.5 & 8.7\end{array}$

aTosoh Corporation, Atlanta, GA.

bMalakoff Industries, Inc., Malakoff, TX.

cThis study; see text for details. 
Table 2. Critical maximum loading $\mathrm{pH}$ values from Figure 2

$\begin{array}{lcccc}\text { Powder } & \begin{array}{c}\text { Regions } \\ \stackrel{11}{\longrightarrow}\end{array} & \begin{array}{c}\text { Regions } \\ \Perp \Perp N\end{array} & \begin{array}{c}\text { Minimum } \\ \text { Loadina }\end{array} & \begin{array}{c}\text { Useful Gelcasting } \\ \text { Range }^{a}\end{array} \\ \mathrm{ZrO}_{2} & 5.5 & 12.0 & 7.0 & \leq 3.3 \\ \mathrm{Al}_{2} \mathrm{O}_{3} & 6.2 & 12.6 & 8.2 & \leq 6.5 \\ 20: 80 \mathrm{ZrO}_{2}: \mathrm{Al}_{2} \mathrm{O}_{3} b & 5.6 & 12.6 & 8.1 & \leq 5.8\end{array}$

aMaximum loading $\geq 50$ vol $\%$.

bBased on vol \%. 


\section{REFERENCES}

1. M. A. Janney, "Method for Moiling Ceramic Powders," U.S. Patent No. 4,894,194, January 16, 1990.

2. O. O. Omatete, A. C. Young, M. A. Janney, and U. H. Adair, "Investigation of Dilute Gelcasting Alumina Suspensions, " pp. 537-44 in Ceramic Powder Science III, Ceramic. Trans., Vol. 12, G. L. Messing, S. H. Hirano, and H. Hausner, ef., The American Ceramic Society, Inc., 1990.

3. A. C. Young, O. O. Omatete, M. A. Janney, and P. A. Menchhofer, "Gelcasting of Alumina," accepted for publication, J' Am. Ceram. Soc. 74, 1991.

7. A. Bleier and C. G. Westmoreland, "Fheolngical and Related Colloidal Aspects of Aqueous Processing that Affect the Development of Microstructure," pp. 185-90 in Better Ceramics through Chemistry IV, B. J. J. Zelinski, C. J. Brinker, D. E. Clark and D. R. Ulrich, eds., Mater. Res. Soc. Symp. Proc., Vol. 180, Materials Research Society, Pittsburgh, PA, 1990.

5. A. C. Young, private commuitication, July 27, i990.

5. A. Bleier and C. G. Westmoreland, "Chemical and Physical Principles of Processing that Affect Microstructure of $\mathrm{Al}_{2} \mathrm{O}_{3}-\mathrm{ZrO}_{2}$ Composites," Mater. Res. Soc. Symp. Proc. 121, 145-54, 1988.

7. S. Usui, "Heterocoagulation," pp. $223-266$ in Progress in Surface and Membrane Science, Vol. 5, J. F. Danielli, M. D. Rosenberg, and D. A. Cadenhead, eds., Acadernic Press, New York, NY, 1972.

8. B. V. Deraguin, "Theory of Heterocoagulation, Interaction, and Mutual Adhesion of Different Particles in Electrolytic Solution," Colloid J. USSR 16, $403-415,1954$.

9 B. V. Deraguin, "A Theory of the Heterocoagulation, Interaction, and Adhesion of Dissimilar Particles in Solutions of Electrolytes," Discusj. Faraday Soc. 18, 85 - 98, 1954. 
10. A. Bleier and E. Matijevic, "Heterocoagulation. I. Interactions of Monodispersed Chromium Hydroxide with Polyvinyl Chloride Latex," J. Colloid Interface Sci. 55(3), 510-24, 1976.

11. A. Bleier and E. Matijevic, "Heterocoagulation. III. Interactions of Polyvinyl Chloride Latex with Ludox HS Silica," J. Chem. Soc., Faraday Trans. 74, 1346-59, 1978.

12. A. Bleier and E. Matijevic, "Stability of Mixed Colloidal Dispersions," Chemistry of Waste Water Technology, pp. 81-98, A. J. Rubin, ed., Ann Arbor Science Publ. Inc., Ann Arbor, MI, 1978.

13. E. Matijevic and A. Bleier, "Heterocoagulation, IV. Stability of Polyvinyl Chloride Latex and Ludox Hs Silica in the Presence of Alumina Species," Croat. Chem. Acta 50(1-4), 93-105, 1977.

14. O. O. Omatete, R. A. Strehlow, and C. A. Walls, "Gelcasting of Submicron Alumina, Sialon, and Silicon Nitride Powders," Proc. of the 37th Sagamore Army Materials Research Conference, Plymouth, MA, 1990. 
(a)

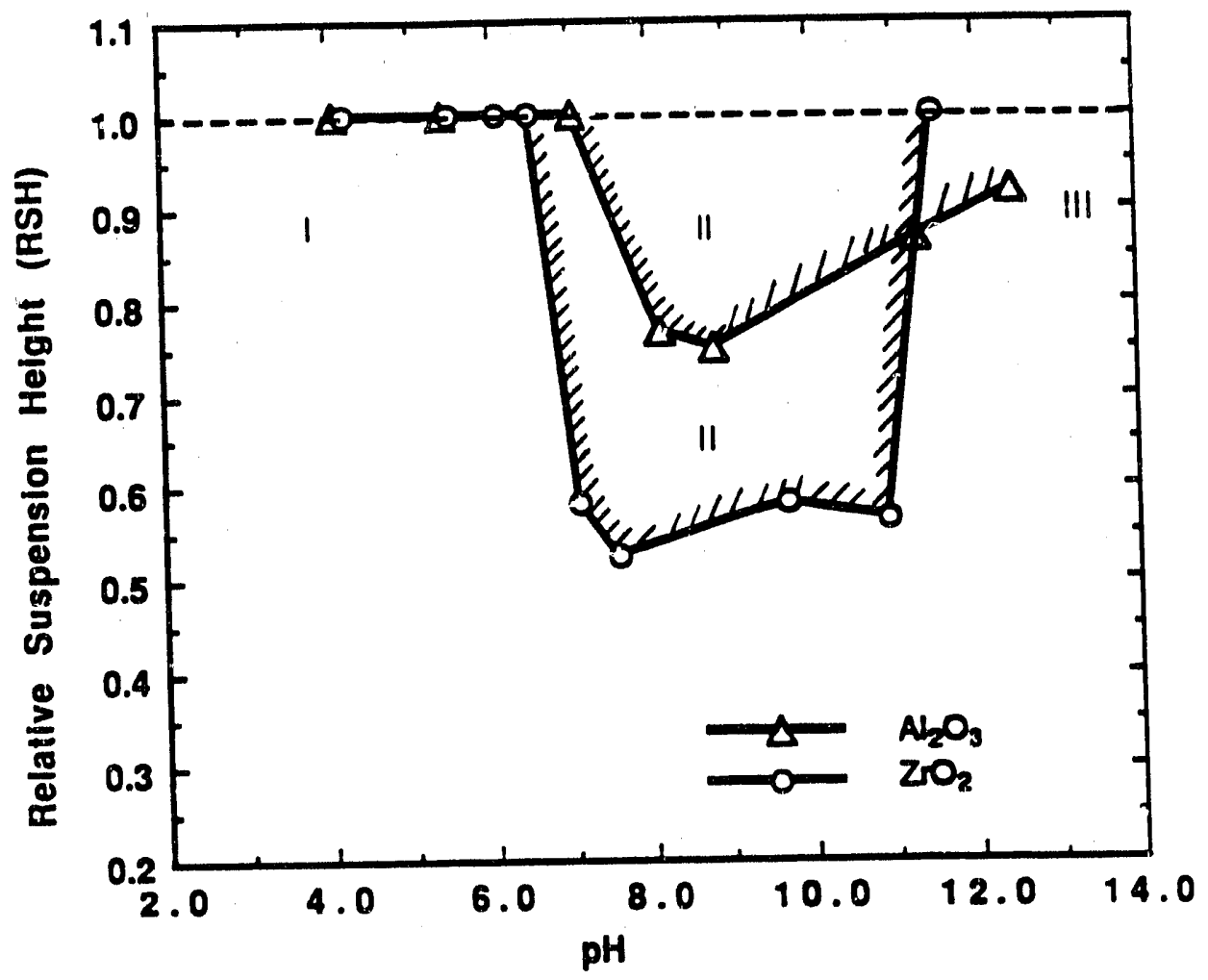

(b)

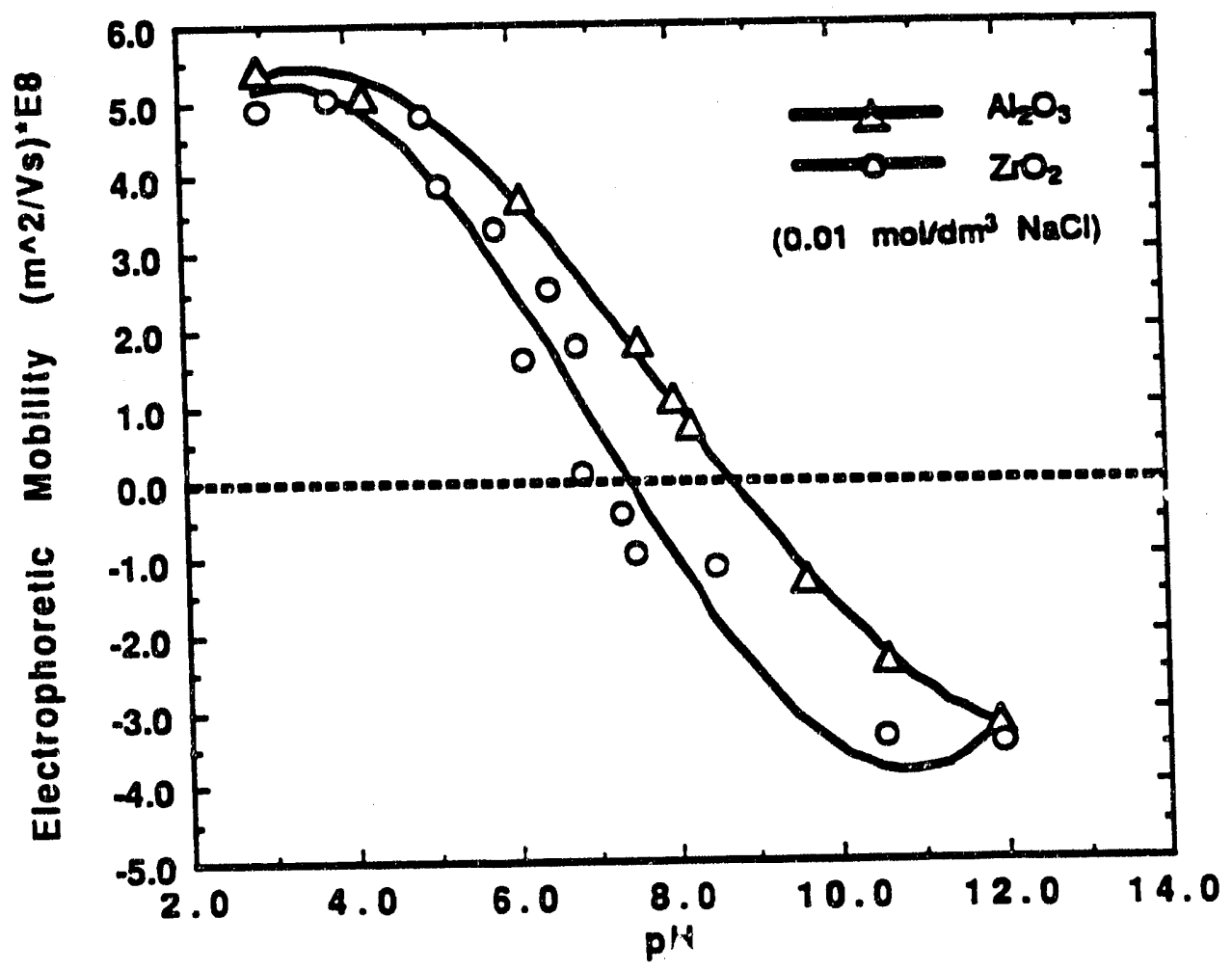

Fig. 1. (a) Sedimentation behavior of unary $\mathrm{ZrO}_{2}$ and $\mathrm{Al}_{2} \mathrm{O}_{3}$ suspensions initially at 3.5 and 5.0 vol \% respectively. Relative Suspension Height (RSH) vs $\mathrm{pH}$ after $1 \mathrm{~h}$, (b) Electrophoretic mobility, $\mu \mathrm{E}$. of $\mathrm{ZrO}_{2}$ and $\mathrm{Al}_{2} \mathrm{O}_{3}$ suspensions in $0.01 \mathrm{~mol} / \mathrm{dm}^{3} \mathrm{NaCl}$ vs $\mathrm{pH}$. 


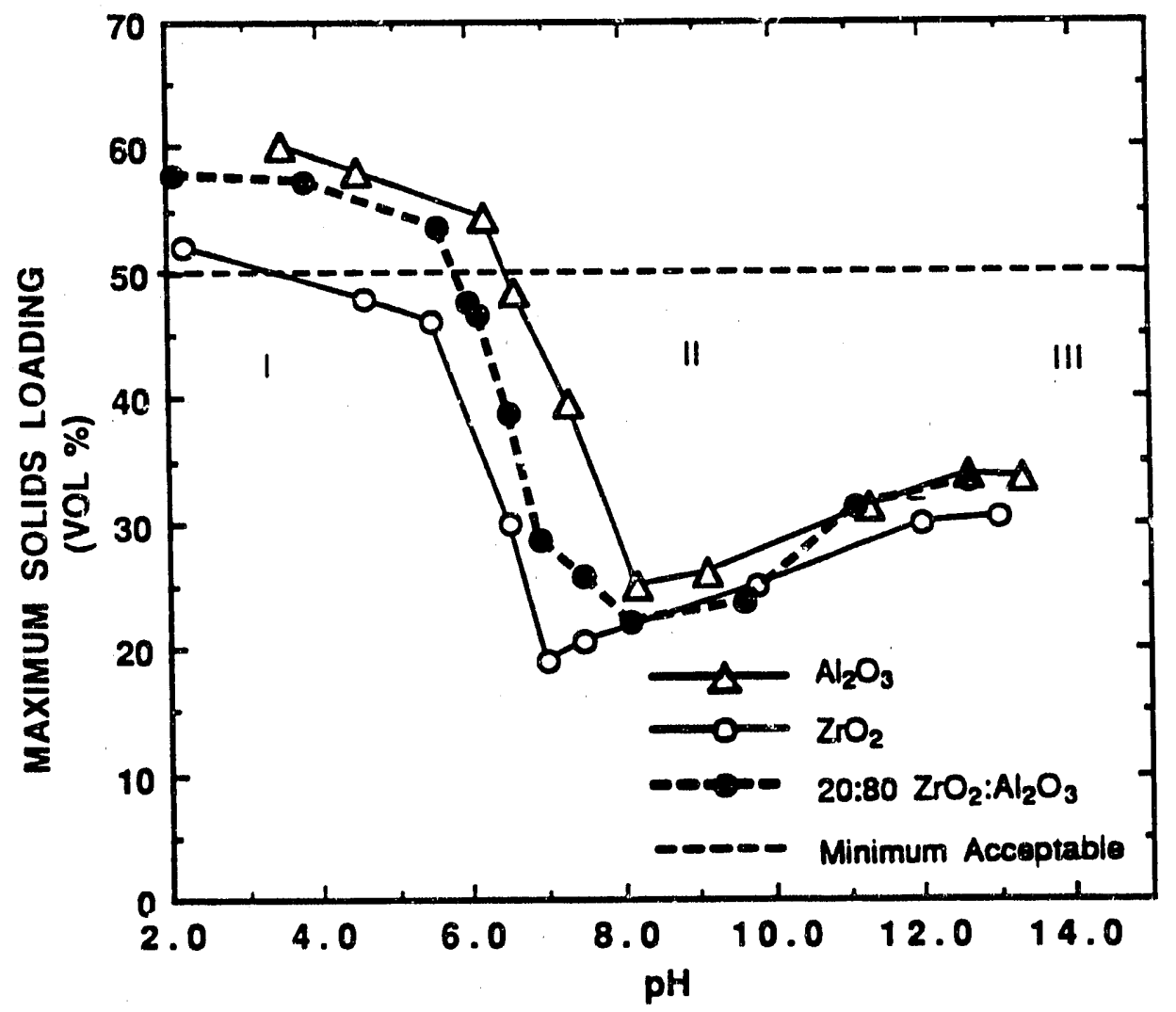

Fig. 2. Maximum loading for $\mathrm{ZrO}_{2}$ (open circles), $\mathrm{Al}_{2} \mathrm{O}_{3}$ (open triangles), and a binary mixture, $1: 4$ (solid circles) $\mathrm{ZrO}_{2}: \mathrm{Al}_{2} \mathrm{O}_{3}$, vol \% of overall mixture vs $\mathrm{pH}$. 


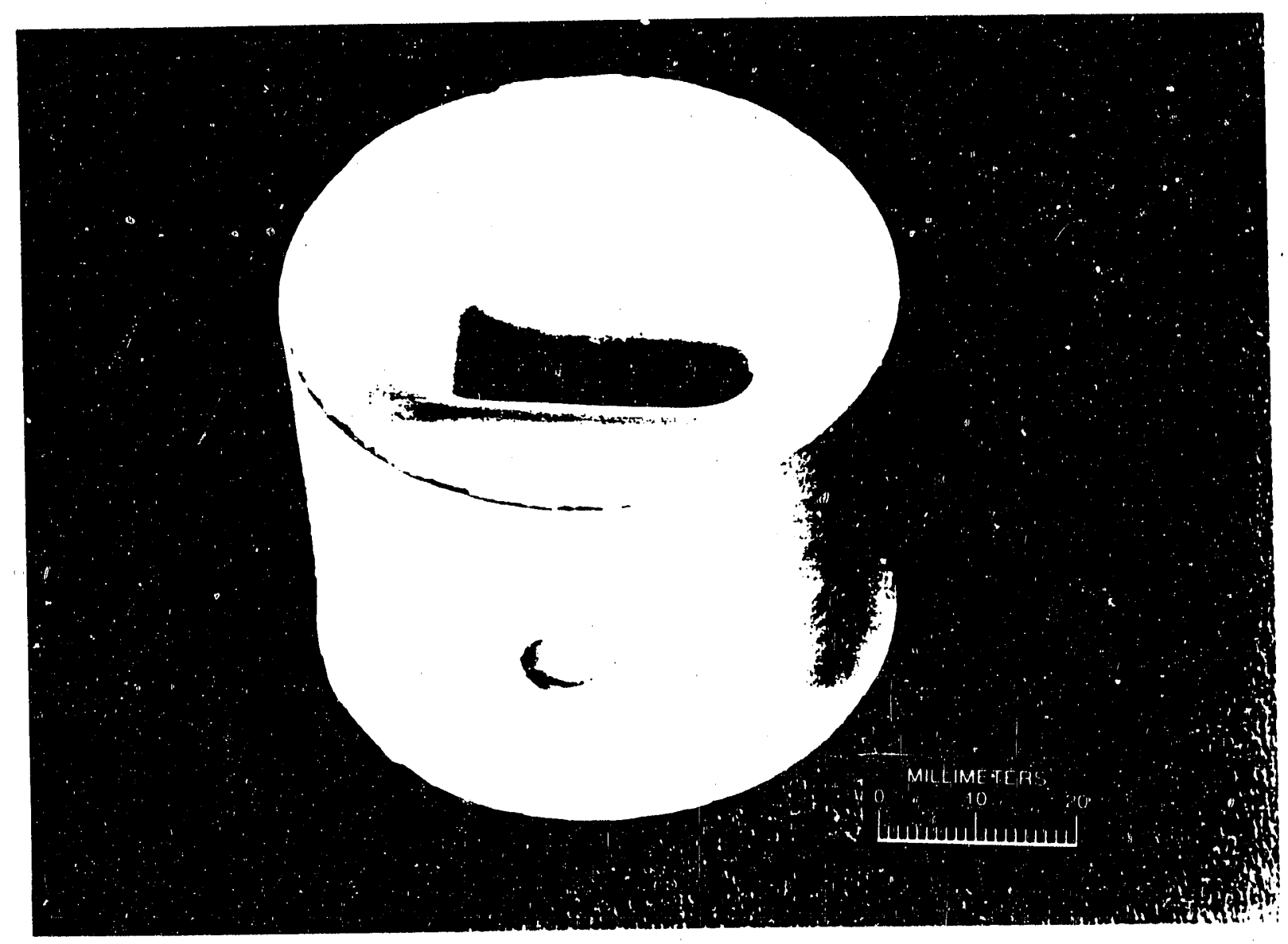

Fig. 3. Dried, composite piston, gelcast from $20: 80$ vol \% $\mathrm{ZrO}_{2}-\mathrm{Al}_{2} \mathrm{O}_{3}$ suspension. 

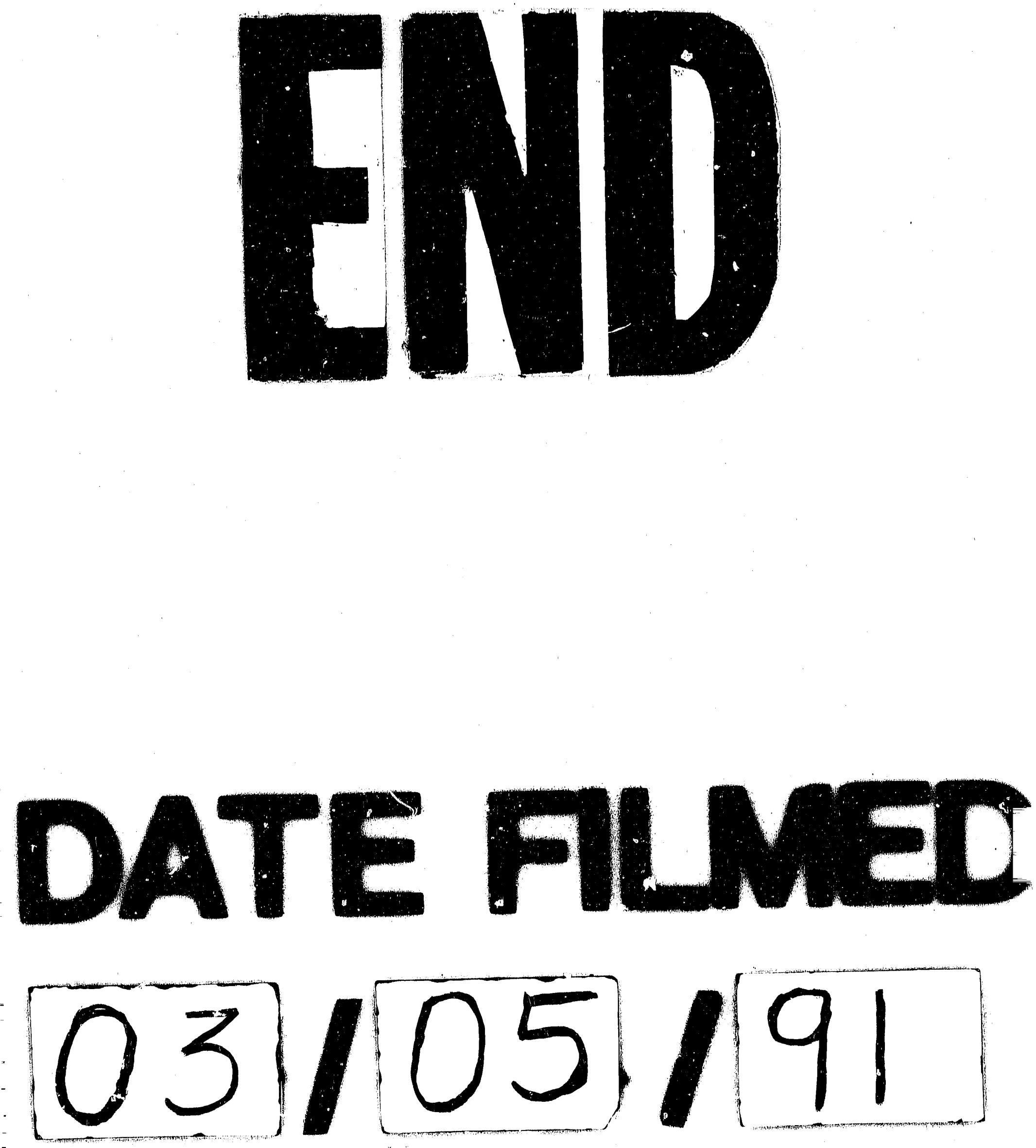
